\title{
Top Ten Reasons a Graduate Student Should Apply to be an ECT Foundation Intern
}

By Cindy S. York

decided to use my opportunity to write this column for TechTrends to encourage graduate students to apply for the ECT Foundation Internship. The following is a list of the top ten benefits the internship offers your career.

10.Funding. As all graduate students can attest, locating funding to attend conferences is tough. I search for every award or travel grant I can so I can attend AECT every year. The internship provided housing, registration, and a stipend (airfare and food) for the AECT convention.

9. Publication. I didn't realize when I won the internship that part of the award was the opportunity to write an article published in TechTrends. I decided to help other graduate students see the value in applying for the internship. My mantra for applying for awards is: Apply for every award you can, you might win. I'm still in awe that I got to be part of the 2008 intern class!

8. Public Speaking. I was nervous when told to sit and talk with people I didn't know at the Leadership Dinner. My thanks to those who made me feel comfortable at a dinner that could have been a very quiet one for me. Additionally, the internship provides the opportunity for you to chair a session and even present with your intern class at the Graduate Student Assembly. We spoke about strategies to successfully complete graduate school.

7. Service Project. As an intern class, you are able to give back to the ECT Foundation and AECT by completing a service project. The 2008 intern class is currently involved in

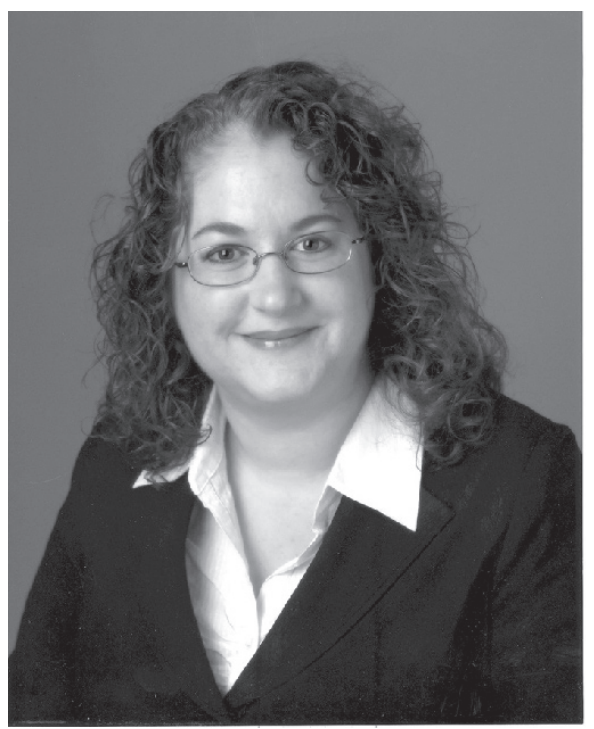

Cindy S. York

two projects. The first will make more graduate students aware of the internship through a flyer sent to all universities. The second is a mentoring project that pairs faculty and graduate students with similar research or teaching interests.

6. Shadowing. In addition to breakfasts with leaders in the field, interns can choose an AECT leader to shadow during the convention. I chose not to follow just one person but instead went to as many board meetings and presentation sessions as I could.

5. Behind the Scenes Pass. The intern medal is an open door pass for the convention. You can attend any meeting you like, a valuable experience for observing how AECT happens. I never would have thought of attending a board meeting prior to the internship.

4. Leadership Opportunities. My intern class engaged in many leader- ship opportunities. In addition, I was invited to join the AECT Leadership Development Committee, which deals with the Summer Leadership Institute. Without the internship, I wouldn't have known how to get involved in something like this.

3. Mentoring. The internship not only provides opportunities to find a mentor (if you don't already have one), but also provides experience and knowledge to return to your university and mentor junior graduate students.

2. Networking. I had the chance to meet many people and form relationships that will last a lifetime. As an intern I had the courage to walk up to people and introduce myself. Excitingly, I met the past, current, and future leaders of AECT and I am no longer just a face in the crowd.

And the number one reason you should apply to be an ECT Foundation intern...

1. It could change your life. It changed mine.

A special thank you to Sandie Waters for everything!

For more information about the ECT Foundation internship program, see http://www.aect.org/ect/ect.asp or contact Dr. Sandie Waters at sandie. waters@gmail.com.

Cindy S. York is a Ph.D. candidate at Purdue University. Her research interests include instructional design heuristics, online learning, and technology integration. She expects to complete the degree requirements in December 2009. With the goal of working at a research university. 